George F. Bass

\section{Comments on James Delgado's Plenary Address}

When I heard James Delgado's brilliant plenary address at Salt Lake City, I was overwhelmed by optimism for the future of our field, partly because I had not realized how accurately the past of that field has been preserved, especially the history of the very conferences of which the Salt Lake City conference was but one-there is much anecdotal misinformation about how CUA began. I liked Delgado's vision of the future, and his suggestions for keeping us on the right track.

Now that I have read his address, I am also struck by Delgado's understanding and explanation of how the field has diverged into various sub-branches as it has matured, his knowledge of particular sites and agencies that have moved it forward, and of the educational programs and practices that increasingly teach both the public and other archaeologists about underwater, maritime, and nautical archaeology. His plea for publications, museum displays, and television programs should not go unheeded, for I have long shared his belief that we will win the war against treasure hunting as much by setting the right examples as by writing new laws.

I have been asked to comment on James Delgado's paper, but after reading it half a dozen times, and thinking about it for several weeks, I have concluded that it could not be better. Although it could be expanded into a book, I can think of no criticism of it as a paper, nor needed augmentation, no area has been neglected. It should, indeed, stand as a manifesto for the field of underwater archaeology. I am just jealous that I never said it all so well.

George F. BASS

InSTITUTE of NaUtical ARchaeology

TEXAS A\&M UNIVERSITY

College Station, TX 77843-4352 